\title{
Lusioersily
}

\section{Nurses' knowledge and attitudes towards pain assessment for people with dementia in a nursing home setting.}

Burns, M., \& Mcllfatrick, S. (2015). Nurses' knowledge and attitudes towards pain assessment for people with dementia in a nursing home setting. International Journal of Palliative Nursing, 21(10), 479-485. https://doi.org/10.12968/ijpn.2015.21.10.479

Link to publication record in Ulster University Research Portal

\section{Published in:}

International Journal of Palliative Nursing

Publication Status:

Published (in print/issue): 27/10/2015

DOI:

10.12968/ijpn.2015.21.10.479

\section{Document Version}

Author Accepted version

\section{General rights}

Copyright for the publications made accessible via Ulster University's Research Portal is retained by the author(s) and / or other copyright owners and it is a condition of accessing these publications that users recognise and abide by the legal requirements associated with these rights.

\section{Take down policy}

The Research Portal is Ulster University's institutional repository that provides access to Ulster's research outputs. Every effort has been made to ensure that content in the Research Portal does not infringe any person's rights, or applicable UK laws. If you discover content in the Research Portal that you believe breaches copyright or violates any law, please contact pure-support@ulster.ac.uk. 
Title: Nurses’ knowledge and attitudes towards pain assessment for people with dementia in a nursing home setting.

Authors

*McIlfatrick SJ, Prof, BSc, MSc, PhD, Reader , Institute of Nursing and Health

Research, University of Ulster, United Kingdom

Burns, ML. BSc, MSc, Macmillan Clinical Nurse Specialist, Belfast Health and Social Care Trust, Northern Ireland.

*corresponding author

Room 12 J11, University of Ulster, Shore Road, Newtownabbey, BT37 OQN.

Email: sj.mcilfatrick@ulster.ac.uk

\section{ACKNOWLEDGEMENTS}

The research team wish to acknowledge Barry et al (2012) for the use of the questionnaire, which was modified for this study. They would also like to thank the nursing staff who completed the survey.

\section{FUNDING}

Macmillan Cancer Support NI provided a small educational grant to undertake this study. 


\section{ABSTRACT}

Aim: The aim of this study was to determine nurses' knowledge and attitudes towards pain assessment for people with dementia in a nursing home setting.

Background: Pain is highly prevalent among older people, yet is often under recognised and under treated in people with dementia. People with dementia can lose the ability to report pain and it is the role of the nurse to identify and appropriately assess pain in order to provide effective treatment. This requires nurses to have sufficient knowledge and training in the assessment and management of pain, however research suggests deficits in this area.

Methods: A cross sectional survey design was used to determine nurses' knowledge and attitudes to pain assessment in dementia. A questionnaire comprising three sections was distributed to 96 registered nurses located across 17 nursing homes in a health care trust in a region in the UK.

Results: A total of 32 responses were obtained (response rate 33\%). The majority of nurses had a good knowledge in relation to the assessment and management of pain in residents with dementia. There was, however, some uncertainty amongst nurses over analgesic choice; the safety of opioid use in dementia; and the use of dementia specific pain assessment tools for residents with no cognitive impairment. The main barriers to effective pain assessment for older people with dementia were work load pressures, poor staffing and lack of medical support.

Conclusion: This study highlighted the need to develop pain education programmes and clear guidance specifically designed for nurses caring for older people with dementia. It also emphasised the need for better communication and co-ordination of pain treatment for nursing home residents with dementia.

KEYWORDS - Dementia, nursing home, pain assessment, knowledge, older people and attitudes. 


\section{INTRODUCTION}

Over the next 40 years, it is anticipated that globally it is anticipated the number of dependent older people will increase signficantly with from 101 million in 2010 to 277 million by the year 2050. Of these approximately $50 \%$ of this population experiencing will experience some form of dementia (Alzheimer's Disease International, 2013). Within the UK there has been a significant shift in health and social care services from hospital to community informed by policy following local strategic reform in order to provide an equitable service (DHSSPSNI, 2011; DOH, 2012). This presents challenges for long-term care settings not only due to the increasing prevalence of the older people but also and-the existence of co-morbidities (European Commission of Health, 2013). It is estimated that 80\% of residents in 
nursing homes have a form of dementia or cognitive impairment (Alzheimer's Society, 2009). The challenge for nursing homes is to provide quality care through effective symptom management for people with dementia.-

Research suggests that whilst The experience of -pain is highly prevalent among nursing home residents (Pautex et al, 2005; Asghari et al, 2006; Leoang and Nuo, 2007; Horgas et al, 2008), and-it is often not recognised and under treated in people with dementia (Closs et al, 2004; Husebo et al, 2008; Reynolds et al, 2008). People with dementia can lose the ability to self-report pain (Herr et al, 2006), it is therefore the role of the nurse to identify and appropriately assess pain in order to provide effective treatment. This requires nurses to have sufficient knowledge and training in the assessment and management of pain for people with dementia however research suggests there are deficits in this area (Jones et al, 2004; Zwakhalen et al, 2007;Barry et al, 2012;Barry et al, 2013). The purpose of this research is to determine the knowledge and attitudes of registered nurses working in a nursing home setting towards pain assessment in residents with dementia.

\section{BACKGROUND}

There are numerous-definitions of pain hich collectively suggest that it is a complex phenomenon, which presents as an unpleasant sensory experience which is uniquely individual (McCaffery et al; 1990; Bonica; 1990; Merskey and Bogduk, 1994). It cannot be adequately defined, identified, or measured by the observer due to the subjectivity of the experience. Therefore pain has often been defined as 'pain is what the patient says hurts' (Forbes and Faull, 1998).

When pain is not treated effectively is can cause not only physiological responses, such as Pain which is ineffectively treated has the potential to cause physchologicat responses such as fear, anxiety and depression, and impact on. It can also affect activities of daily living, such as mobility, appetite and sleep. Unrelieved pain can also result in an individual experiencing distressing cognitive impairment, such as disorientation, mental confusion and a reduced ability to concentrate (Riva et al, 2011). For individuals with existing cognitive impairment such as dementia, the experience of pain can manifest into behavioural disturbances such as agitation and 
aggression (Cohen-Mansfield, 2004). This can lead to increased distress not only for the individual but also for their care givers (Husebo et al, 2008). According to Nygaard and Jarland (2005), pain in people with dementia can often be undetected with anti-psychotic drug use being first line for the management of agitation (Husebo et al, 2011). Therefore it can be argued that the overall effective management of undiagnosed pain can reduce behavioural disturbances and distress (Calvin, 2011; Husebo et al, 2011; Ahn and Horgas, 2013).

Pain assessment in people with dementia is particularly challenging due to the difficulty for the individual remembering their pain, interpreting the question and maintaining information (Scherder et al, 2005; Cohen-Mansfield, 2005). Therefore assessment of pain in dementia largely relies on emotional and behavioural observation, as individuals lose the ability to self-report pain (Monroe et al, 2012). There are a number of tools are available for the assessment of pain in dementia (Morello et al, 2007; Lin et al, 2011), but the quality and utility of these tools have been widely debated (Buffum et al, 2007; Fuchs-Lacelle et al, 2008;Cohen-Mansfield, 2013). Nurses play a key role in the management of pain through the utilisation of pain assessment tools, behavioural observation, and analgesic choice; however it has been identified that lack of knowledge, training and negative attitudes towards pain in dementia has been a barrier to effective pain management (Jones et al, 2004; Zwakhalen et al, 2007; Barry et al, 2012; Barry et al, 2013). Therefore there is a need to examine nurses' knowledge and attitudes towards pain assessment for people with dementia.

\section{AIM:}

The aim of this study was to determine nurses' knowledge and attitudes towards pain assessment for people with dementia in a nursing home setting.

\section{Objectives:}

1. To explore nurses' knowledge about pain assessment for people with dementia.

2. To determine the factors that may influence their knowledge and attitudes towards pain assessment for people with dementia. 
3. To identify nurses' current level of training and education in pain and dementia.

4. To explore the perceived barriers of effective pain assessment.

5. To make recommendations for future learning and practice development in nursing homes settings for pain assessment for people with dementia.

\section{METHODS}

Design: A cross sectional survey design was used for the proposed study to determine eurrent knowledge and attitudes to pain in dementia. The data was collected over a period of four weeks with nurse managers acting as link nurses for the local distribution of the questionnaires.

\section{DATA COLLECTION}

The three-part questionnaire was adapted from a previous study conducted by -Barry et al (2012) focusing on nurse managers' knowledge and attitudes to pain in nursing home residents with dementia (Table 1). Section one recorded demographic information and general information regarding pain assessment in the nursing home. Section two consisted of 27 statements divided into four parts, each of which concerned with a different aspect of pain in residents with dementia. These included statements in which the participant indicated how strongly they agree or disagree using a Likert scale. Section three adopted an open ended question style to record the participant's current level of training and identified areas of future learning and development. Face and content validation of the questionnaire was undertaken through peer review and was previously determined by Barry et al (2012).

Insert table 1

\section{SAMPLE}

The sample was for this study comprised of-registered nurses who were-working in nursing homes in a targeted area of a health care trust in a region in the UK. It was noted that there were 51 nursing homes in total in the Health care Trust, regulated and inspected by the Regulation and Quality Improvement Authority (RQIA). Owing to 
limitations of time and resources it was decided to restrict the distribution of the questionnaire to a focused geographical area. This smaller geographical area comprised 17 nursing homes with a target population of ninety-six registered nurses.

The inclusion criteria included: identified aimed to target-registered nurses who had [smc1]-experience working in a nursing home setting; who had been working in the home for at least 6 months, inducted into the home and therefore should have been familiar with nursing home policies and guidelines; and would regularly care for people with dementia. Exclusion criteria included: Nursing home managers excluded as it was considered they fulfilled a different role with regards to pain management and research that had been conducted with this target group previously (Barry et al; 2012). _Agency nurses/ Bank Nurses/ \& nurses working learning disability units. This was because were also excluded, as they may not regularly care for residents with dementia

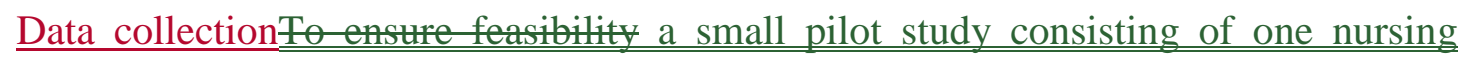
home was undertaken. from the Eastern area of the Health care Trust was completed over a 2 week period with one telephone reminder at the end of week one. The data was collected over a period of four weeks with nurse managers acting as link nurses for the local distribution of the questionnaires. The participant information sheet and questionnaires was distributed to all nurses in each homes nursing to enable participants to decide if they are eligible and willing to complete it. Completed questionnaires were returned in a stamped address envelope to ensure confidentiality and anonymity. To ensure an adequate response rate a weekly telephone reminder to each of the participating nursing home managers was initiated at the end of week two. To ensure feasibility a small pilot study consisting of one nursing home from the

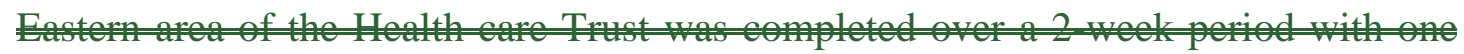
tephone reminder athend of one-

\section{DATA ANALYSIS}

Data was Information collected from the questionnaire was-coded and entered into Statistical Package for Social Sciences (SPSS) software for analysis. The-use of nonparametric statistics such as crosstabulations identified relationships between the 
independent variable such as age; years of experience; years working in nursing home, against the mean belief score. The use of Kruskal-Wallis and Mann-Whitney tests identified differences between place of education, training, experience and the use of pain guidelines. Open-ended questions from the questionnaire were content analysed for themes using thematic analysis.

\section{ETHICAL CONSIDERATIONS}

The survey assured anonymity and confidentiality for the participant. Informed consent was implied through the participant's completion and return of the questionnaire. Ethical approval was obtained from the University ethics committee prior to the beginning of the study.

\section{RESULTS}

A total of 32 questionnaires were returned, providing a response rate of 33\% (32/96).

\section{Demographic data}

The majority of respondents were female $(n=27)$ with an average age of 41 years and most had received their nursing education outside the United Kingdom or Ireland $(n=20)$. Most of the respondents were band 5 registered nurses (78\%) working full time (84.4\%) in private nursing homes, with an average of 8.6 years experience working in this setting. The respondents had an average 18.4 years experience from qualification (ranging from 2 to 39 years) and an average of 7.5 years caring for older people with dementia. It was found that $96.6 \%$ of the nursing homes provided care for residents with dementia, with $68.8 \%$ of respondents identifying the routine use of pain treatment guidelines in these homes. (Table 2) However, when identifying pain treatment guidelines respondents commonly reported the use of the Abbey pain scale.

With regards to knowledge it was found that the nurses score ranged from 63 to 87 out of a possible 100, with a the mean total score of 74 . This indicated an overall good knowledge base in relation to the assessment and management of pain in residents with dementia. 
Insert table 2

\section{Presence of Pain in Dementia}

It was identified that $50 \%$ respondents considered that pain was not a natural consequence of aging. It was found that nurses who had more experience caring for people with dementia $(\mathrm{p}=0.563)$ and those who were qualified longer did not agree that pain was a consequence of age $(p-0.731)$. However, using crosstabulations these findings were not statistically significant. A large proportion of respondents $(n=23)$ felt that dementia could affect the physiological processing of pain and that the perception of pain in dementia was different to that of a cognitively intact resident $(\mathrm{n}=$ 12). The majority of respondents $(n=29)$ also recognised that pain in residents with dementia may be evident through a change in behaviour. There was however uncertainty and disagreement that residents with dementia are more likely to experience pain than cognitively intact residents (figure one).

Insert figure 1

\section{Pain Assessment}

Most respondents $(n=29)$ recognised the difficulty in identifying pain in residents with dementia. The majority of respondents $(n=25)$ thought that people with dementia could not accurately provide a self-report of pain. There was uncertainty in the use of pain assessment tools; whilst the majority of respondents $(n=27)$ were aware of the use specific pain assessment tools for people with dementia, it was found that they were not routinely used in some nursing homes $(n=6)$. Nurses who routinely used pain assessment guidelines demonstrated a stronger knowledge of pain assessment in dementia than nurses that did not use guidelines ( $p=0.287)$, however with the use of Mann Whitney test this does not appear statistically significant ( $p=0.287)$, There was also some disagreement or uncertainty from respondents $(n=8)$ over the non-use of standard pain assessment tools for residents with cognitive impairment. The majority of respondents indicated the use of the Abbey Pain Scale for residents with dementia, however some respondents also suggested the use of the Abbey pain scale for residents with no cognitive impairment. All respondents recognised the importance of physiological indicators of pain when assessing residents with dementia. The majority 
of nurses $(n=28)$ also identified the importance of family/care givers report when assessing pain in dementia. (Figure 2)

\section{Insert figure 2}

\section{Management and treatment of pain people with dementia}

Most nurses ( $\mathrm{n}=29$ ) felt strongly that residents with dementia who were experiencing pain should be managed differently to cognitively intact residents. The majority of nurses $(n=28)$ agreed that the treatment of pain in dementia should follow a step-wise approach._- Hhowever almost one third of nurses (31.3\%) were uncertain whether optimal pain treatment was achieved with regular analgesics. Respondents were also unsure about the safety of using opioids in residents with dementia in regards to increased risk of side effects and addiction. Respondents who had not attended training over the past 2 years were less sure of the management and treatment of pain in dementia $(p=0.065)$. Nurses who had received their training in Australia $(n=2)$ and the UK $(n=12)$ had the highest mean belief score in relation to optimal pain management in dementia. Most respondents $(n=29)$ agreed that non-pharmacological methods of pain control are useful in the management of pain in dementia. (Figure 3)

Insert figure 3

\section{Perceived barriers to optimal pain management}

\section{Respondents had a high level of agreement with the perceived barriers to optimal pain} management (table 3). The most common barriers identified were poor staffing levels within the care home $(n=29)$ and lack of time to effectively assess pain $(n=26)$. The longer the nurses were employed within the nursing home the stronger agreement to the perceived barriers to effective pain assessment ( $\mathrm{p}=0.903)$, however, using erosstabulations this relationship is not statistically significant. Following the use eontent analysis-respondents also identified that residents with dementia ean lacked understanding in relation to their pain management resulting in refusal of analgesia and increased resident anxiety. Respondents also identified lack of GP support and pain treatment delays as barriers to effective pain management table 3)..

Insert table 3 


\section{Training and education}

It was found that most of the nurses $(n=20)$ had received training on pain in people with dementia. Courses attended mainly included palliative care training sessions provided by the community palliative care facilitators or training by local hospice services. Nurses who had received training on pain in dementia scored higher in relation to the management and assessment of pain than nurses who had not received any training $(\mathrm{p}=0.039)$. For those who had not received training they identified lectures (26.6\%), study days (25\%) and distance learning (16.7\%) as the best methods of facilitating learning. When nurses were asked to identify their learning needs; pain management at end of life in dementia, knowledge of analgesic choice, and a better understanding pain assessment tools were had been-identified. Some nurses also suggested the need for better quality education on dementia care and pain management.

Discussion: Overall the majority of nurses had good knowledge about in relation to the-assessment and management of pain in residents with dementia. This study highlighted some reservation among nurses over analgesic choice, the safety of opioids, and suitability of pain assessment tools in residents with dementia. These findings are similar to international studies (Zwakhalen et al, 2007; Barry et al, 2012; Brorson et al, 2014) which emphasises need for clear guidance and training for nurses caring for nursing home residents with dementia. Whilst these findings are similar reflect similarly-to international studies; this study has further-identified the lack of interdisciplinary support and communication as barriers to effective pain management.

The findings from this study showed It is apparent from this study that nursing home nurses were aware of the importance of behavioural cues when assessing and identifying pain in people with dementia. When asked about how nursing home staff assess pain forin residents with dementia; the majority identified agitation, loss of appetite, reduced mobility, change of facial expression and vocalisation as pain indicators. Respondents also appeared to have a good knowledge of the pain experience of residents with dementia that is similarly indicated in the literature (Barry et al, 2012; Chang et al, 2011). 
Previous studies have-indicated that amount of experience and length of time qualified are important influencing factors on nurse's knowledge and attitudes of nurses (Cohen-Mansfield and Creedon, 2002; Chang et al, 2011; Barry et al, 2012). Whilst a similar finding was noted this aspect-was not statistically significant in this area. This-may indicate that nurses have a good awareness of the presence of pain in people with dementia, which is not influenced by nurses' experience. Although nurses may recognise the importance of pain assessment in dementia; studies suggest they lack confidence in distinguishing between pain and other problems such as delirium resulting in the misdirection of treatment (Martin et al, 2005; Cohen Mansfield and Creedon, 2002; Kovach et al, 2000).

It was found that the nurses in this study considered that traditional models of pain assessment tools could not be used for residents with dementia. Rather they indicated that dementia specific pain assessment tools, such as the abbey pain scale, [smc2]were being used for residents with no cognitive impairment. It is also noted in this study that pain assessment tools are not regularly utilised in clinic practice (18.7\%), which has been also identified in previous studies (Kaasalainene et al, 2007; Martin; 2005). An effective assessment requires the use of an adequate pain assessment tool specifically designed for dementia. There are a number of validated pain assessment tools for people with dementia (Lin et al, 2011; Morello et al, 2007) however the quality and utility of these tools have been widely debated (Cohen-Mansfield, 2013; Fuchs-Lacelle et al, 2008; Buffum et al, 2007). Nurses expressed the need for better and more accessible pain assessment tools in practice. This is similar to the international studies in this area (Martin et al, 2005; Barry et al, 2012). Yet whilst the need for tools is advocated this needs to be supported with training and education, not only in the use of the tools but for evidence based guidelines to change clinical practice.

It was interesting to note that the nurses who had received recent training from local hospice services or educational facilitators had a better understanding of optimal pain management in residents with dementia. When asked about types of education provision nurses indicated the need for formal education, seminars and courses on pain management in dementia. These approaches are not available to staff on [smc3]a regular basis. It was also interesting to note that all formal education received had no 
cost implications for nursing homes which may suggest issues of limited resourcing. Studies have identified limited resources as barriers to effective pain management of nursing home resident (Kaasalainene et al, 2007; Brorson et al, 2014). Ideally, better resources would allow for more time for education and the implementation of training in clinical practice. This emphasises the need for on-going support and education for nursing home staff by local trust services; however, this must be tailored to meet the needs of long term care settings. Whilst pain education programmes have been attempted in care homes (Neville et al, 2006), staff shortages and high turnover staff remains an impediment to education and training in long term care facilities. International studies have identified similar findings (Kaasalainen et al, 2007; Brorson et al, 2014). It is also interesting to note that the majority of staff in this study consisted of overseas nurses whose prevalent language may not have been English. This highlights the need for continued facilitation of education programs tailored to meet the needs of staff diversity in this care setting.

The barriers to effective pain assessment most commonly identified in this study relate to time constraints, staff shortages and high workload pressures. This is an emergent theme in several previous studies (Barry et al, 2012, Kaasalainene et al, 2007; Martin et al, 2005). Nurses feel that they have a limited amount of time to accurately assess pain and review treatment (Martin et al, 2005). Time constraints and work load pressures can cause lack of continuity and poor knowledge transfer between staff (Kaasalainene et al, 2007). This has implications on the overall quality of care. Greater workforce stability is required in order to provide continuity of care and increase the likelihood of successful pain detection and assessment. When asked about further barriers nurses identified issues regarding incorrect prescriptions, prescription delays and the lack of GP support in achieving optimal pain management. These findings have been mirrored in previous studies (Blomqvist and Hallberg, 2001; Barry et al, 2012). This highlights the need for better co-ordination and communication of patient care. The use of communication templates specifically focusing on pain assessment, and interdisciplinary flow charts has been recommended to help improve multidisciplinary collaboration (Kaasalainen et al, 2007).

Limitations: The limitations of self-report surveys need to be acknowledged, recognising that it was possible the nurse responded in ways that reflected best 
practice rather than what they actually do. Also the low response rate of $33 \%$ needs to be acknowledged. Nevertheless, it can be argued that this reflect the experience of similar studies conducted in this area. Other potential limitations relate to the questionnaire itself, as whilst it was subject to content validity and was adapted from a previous study it was not tested formally for reliability. This is particularly relevant to estimates of attitude.

Conclusions: Nurses recognized that they couldn't rely on traditional models of pain assessment in dementia; instead they must consider pain indicators such as changes in mood and behavior to provide an accurate assessment. It has been identified knowledge deficits for nurses in relation to the use of pain assessment tools and the optimal treatment of pain in dementia. This study also revealed that limited staffing, lack of interdisciplinary support and workload pressures were are[smc4] perceived barriers to effective pain assessment. Therefore there is a need to develop pain education programs specifically designed for nurses caring for older people with dementia in order to improve knowledge in the effective assessment and management of pain.

Implications for Practice: Education provisions in nursing homes need to be flexible and suited to the Long Term Care (LTC) environment. It highlights the need for clear evidence based guidance in relation to the use of pain assessment in older people with dementia. Further research is required focusing on the co-ordination and communication of care between healthcare professionals caring for people in long term care facilities. Due to the current climate of care provisions in nursing homes there is a need to explore opportmities for better support and greater resources to improve the quality of care for nursing home residents with dementia. 


\section{$\underline{\text { Reference List }}$}

Ahn H., and Horgas, A. L. (2013) The relationship between pain and disruptive behaviour in nursing home residents with dementia. BMC Geriatrics. 13:14,14712318

Alzheimer's Society (2009). Counting the cost. London: Alzheimer's Society. http://www.alzheimers.org.uk/site/scripts/news_category.php?categoryID=200288 Accessed 23/4/14 (internet)

Alzheimers Disease International: World Alzheimers Report 2013. Pg12. www.alz.co.uk accessed 12/12/13 (internet)

Asghari , A.,Ghaderi, N. and Ashory, A. (2006)The Prevalence of Pain among Residents of Nursing Homes and the Impact of Pain on Their Mood and Quality of Life. Arc Iranian Medicine. 9 (4): 368 - 373

Barry H, Parsons C, Passmore P, Hughes C. (2012) An exploration of nursing home managers' knowledge of and attitudes towards the management of pain in residents with dementia. International Journal of Geriatric Psychiatry. 27: 12581266

Barry, H. Parsons, C., Passmore, P., Hughes, C. (2013) Community pharmacists and people with dementia: a cross sectional survey exploring experiences, attitudes, and knowledge of pain and its management. British Journal of Geriatric Psychiatry. 24

Blomqvist, K. and Hallberg, I. R (2001) Recognising pain in older adults living in sheltered accommodation: the views of nurses and older adults. International journal of Nursing studies 38: 305-318

Bonica, J. J. (1990) The Management of Pain. (2nd Ed), Philadelphia: Lea and Febiger.

Brorson, H., Plymoth, H., Ormon, K., Bolmsjo, I (2014) Pain relief at the end of life: nurses' experiences regarding end-of-life pain relief in patients with dementia. Pain Management Nursing; 15:1, 315-323.

http://www.unboundmedicine.com/medline/?st=M\&author=Brorson\%20H 
Buffum, M., Hutt, E., Chang, V. T., Craine, M. H and Snow, L. (2011) Cognitive impairment and pain management: Review of issues and challenges. Journal of Rehabilitation Research \& Development. 44 (2) 315-330

Calvin, H. (2011) Systematic pain management reduced agitation in nursing home residents with dementia. Annals of Internal Medicine . 2011;155(100

Chang, Sung OK; Oh,Younje; Park, Eun Young; Kim Geun Myun; Kil Suk Young.(2011) Concept Analysis of Nurses' Identification of Pain in Demented Patients in a Nursing Home: Development of a Hybrid Model. Pain management nursing, vol 12(2)

Closs, J., Barr, B., and Briggs, M. (2004) Cognitive status and analgesic provision in nursing home residents. British Journal of the Royal College of General Practitioners. 54(509):919-921

Cohen-Mansfield, J. (2013) Even with regular use of an observational scale to assess pain among nursing home residents with dementia, pin-relieving interventions are not frequently used. Evidence Based Nursing.

Cohen-Mansfield, J. and Creedon, M.(2002) Nursing staff members' perceptions of pain indicators in persons with severe dementia. The Clinical Journal of Pain. Vol.18(1) 64-73

Cohen-Mansfield, J. and Libin, A. (2005) Assessment of agitation in elderly patients with dementia: correlations between informant rating and direct observation. International journal of Geriatric Psychiatry. 19: 881-91

Department of Health, Social Services and Public Safety of Northern Ireland (DHSSPSNI) (2011). Transforming Your Care: Review of Health and Social Care in Northern Ireland available at http://www.dhsspsni.gov.uk/index/tyc.htm accessed $\underline{2 / 2 / 14}$

European Commission of Health (2013). A good life in old age? Monitoring and Improving quality in long-term care facilities.

Forbes, K. and Faull, C. (1998) The Principles of Pain Management. In: Faull, C., Carter, Y., Wood, R. $2^{\text {nd }}$ Edition. Handbook of Palliative of Care. Blackwell Science. Oxford.

Fuchs-Lacelle, S. and Hadjistavropoulous, T., Lix, L. (2008) Pain assessment as intervention: a study of older adults with severe dementia. Clinical Journal of Pain. 24(8): 697-707

Herr, K., Coyne, P. Key, T., Manworren, R., McCaffery, M., Merkel, S., PelosiKelley, J. and Wild, J. (2006) Pain assessment in the nonverbal patient: position 
statement with clinical practice recommendations for practice. Pain Management Nursing. 7 (44-52)

Horgas,A.L., Elliott, A.F., Marsiske, M. (2008) Pain assessment in persons with dementia: relationship between self-report and behavioural observation. Journal of the American Geriatric Society. 57(1): 126-132

Husebo, B.S., Ballard, C., Sandvik, R., Nilsen, O.B., Aarsland, D. (2011) Efficacy of treating pain to reduce behavioural disturbances in residents of homes with dementia: cluster randomised clinical trial. British Medical Journal; 343:4065.

Husebo, B.S., Strand, L.I., Moe-Nilssen, R. Borgehusebo, S., Aarland, D., Ljuggren, A.E. (2008) Who suffers most? Dementia and pain in nursing home patients: a cross sectional study. Journal of the American Directors Association. 9(6): 427-433

Jones, K.R., Fink, R., Pepper, G., Hutt, E., Vojir, C.P., Scott, J., Clark, L., and Mellis, K. (2004) Improving nursing home staff knowledge and attitudes about pain.

Gerontologist. 44(4): 469-478

Kaasalainene, S., Coker, E., Dolovich, L., Papaioannou, A. Hadjistavropoulous, T., Emili, A. and Ploeg, J.( 2007) Pain management decision making among long term care physicians and nurses. Western Journal of Nursing Research. Vol 29 (5) 561-580

Kovach, C., Griffie, J., Muchka, S., Noonan, P. and Weissman, D. (2000) Nurses' Perceptions of pain assessment and Treatment in the Cognitively Impaired Elderly: It's not a guessing game. Clinical Nurse Specialist. Vol 14(5) pp. 215-220

Leoang, I.Y. and Nuo, T.H (2007) Prevalence of Pain in Nursing Home Residents with Different Cognitive and Communicative Abilities. Clinical Journal of Pain. 23: $2(119-127)$

Lin, P., Lin, L., Shyu, Y.L Hua, M. (2011) Predicators of pain in nursing home residents with dementia: a cross sectional study. Journal of Clinical Nursing. 20(13/14):1849-57

Martin, R Williams J, Hadjistavropoulos, T. Mac Lean M.(2005) A qualitative investigation of seniors' and caregivers' views on pain assessment and management. The Canadian Journal of nursing research. 37(2) 142-164

McCaffery, M., Ferrell, B., O'Neil, E., Lester, M. and Ferrell, B. (1990) Nurses' knowledge of opioid analgesics and psychological dependence. Cancer Nursing 13, 21-27.

Merskey, H. M., Bogduk, N.(1994) Classification of Chronic Pain. (2nd edition). IASP Press, Seattle, p.211

Monroe, T., Carter, M., Feldt, K. Tolley, B., and Cowan, R.L (2012) Assessing advanced cancer pain in older adults with dementia at the end of life. Journal of Advanced Nursing. 68(9) 2070-2078 
Morello, R., Jean, A., Alix, M., Sellin-Peres, D., Fermanian, J. (2007) A scale to measure pain in non-verbally communicating older patients: the EPCA-2 Study of its psychometric properties. Pain. 133 (1-3) 87-98

Nyaard, H.A. and Jarland, M. (2005) Are nursing home patients with dementia diagnosis at increased risk for inadequate pain assessment? International Journal of Geriatric Psychiatry. 20(8) 730-737

Neville, C., Mc Carthy, A. and Laurent, K. (2006) Pain management skills of regional nurses caring for older people with dementia: a needs analysis. Collegian (Royal College of Nursing, Australia), 13(2):31-36

Plautex, S, Herrmann F, Le Lous P., Fabjan M, Michel, J.P. Gold, G. (2005) Feasibibility and reliability of four pain self-assessment scales and correlation with an observational rating scale in hospitalised elderly demented patients. Journal of Gerontology And Biomedical Science. 60 (524-529)

Reynolds, K.S., Hanson, L.C., DeVellis, R.F., Henderson, M., Steinhauser, K.E (2008) Disparities in pain management between cognitively intact and cognitively impaired nursing home residents. Journal of Pain and Symptom Management. 35 (4) 388-96

Riva, P., Wirth, J., and Williams, K. D. (2011)The consequences of pain: The social and physical pain overlap on psychological responses. European Journal of Social Psychology. 41: 6, 681-687,

Scherder, E., Oosterman, J., Swaab, D et al (2005) Recent developments in pain in dementia. British Medical Journal. 330. 7489: 461-464

Zwakhalen S, Hamers J, Peijnenburg R, and Berger M. (2007) Nursing staff knowledge and beliefs about pain in elderly nursing home residents with dementia. Pain Res Manage 12: 177-184. 